\title{
PERBANDINGAN JUMLAH TROMBOSIT PADA PASIEN DIABETES MELITUS TIPE 2 YANG MENGGUNAKAN ASPIRIN DAN TIDAK MENGGUNAKAN ASPIRIN
}

\author{
${ }^{1}$ Dwi P. Palimbunga \\ ${ }^{2}$ Karel Pandelaki \\ ${ }^{3}$ Arthur E. Mongan \\ ${ }^{3}$ Firginia Manoppo
}

\author{
${ }^{1}$ Kandidat Skripsi FakultasKedokteran Universitas Sam Ratulangi Manado \\ ${ }^{2}$ Bagian Ilmu Penyakit Dalam Fakultas Kedokteran Universitas Sam Ratulangi Manado \\ ${ }^{3}$ Bagian Patologi Klinik Fakultas Kedokteran Universitas Sam Ratulangi Manado \\ Email: dwi.palimbunga@gmail.com
}

\begin{abstract}
Patients with type-2 diabetes mellitus are characterized by an acceleration thrombopoiesis, an increased platelet turnover and a decreased platelet survival time which affect platelet count, that cause the increasing of proportion of large and reactive platelets, and hence more thrombogenic. People with diabetes have a two- to fourfold increase in the risk of dying from the complications of cardiovascular disease. Aspirin therapy is recommended for the primary and secondary prevention of cardiovascular events in most people with diabetes. This study was an descriptive analytic method with cross sectional study design. The subjects in this study involve 112 people, 56 people treated with aspirin, and the 56 others were not who signed in endocrine metabolic department of RSUP Prof. Dr. R. D Kandou Manado. Data were taken from medical record. The Mann-Whitney test showed that there was no significant difference between the platelet count in patients with type-2 diabetes mellitus treated with aspirin and patients who were not. Conclusion: There was no significant difference between the platelet count in patients with type-2 diabetes mellitustreated with aspirin and patients who were not.
\end{abstract}

Key word:Aspirin, Type-2 Diabetes Mellitus, Platelet Count

\begin{abstract}
Abstrak: Pada pasien diabetes melitus tipe-2 terjadi percepatan trombopoiesis, peningkatan pergantian trombosit dan penurunan waktu hidup trombosit yang mempengaruhi jumlah trombosit, yang menyebabkan terjadinya peningkatan ukuran trombosit yang lebih besar dan reaktif, sehingga bersifat trombogenik. Risiko kematian karena komplikasi penyakit jantung meningkat dua sampai empat kali lipat. Aspirin digunakan sebagai pencegahan primer dan sekunder terhadap kejadian kardiovaskular pada pasien diabetes. Tujuan penelitian ini untuk melihat perbedaan jumlah trombosit pada pasien diabetes melitus tipe-2 yang menggunakan aspirin dan tidak menggunakan aspirin. Penelitian ini bersifat deskriptif analitik dengan rancang penelitian cross sectional. Subjek dalam penelitian ini berjumlah 112 orang, 56 orang yang menggunakan aspirin dan 56 orang lainnya tidak menggunakan aspirin yang terdaftar di Poliklinik Endokrin Metabolik RSUP Prof. Dr. R. D. Kandou Manado. Data diambil dari catatan rekam medik. Hasil penelitian menggunakan uji Mann-Whitney,menunjukkan bahwa tidak terdapat perbedaan yang signifikan antara jumlah trombosit pada pasien diabetes melitus tipe-2 yang menggunakan aspirin dan tidak menggunakan aspirin $(p=0,059)$. Simpulan: Tidak terdapat perbedaan signifikan antara jumlah trombosit pada pasien diabetes melitus tipe 2 yang menggunakan aspirin dan tidak menggunakan aspirin.
\end{abstract}

Kata Kunci: Aspirin, Diabetes Melitus Tipe-2, Jumlah Trombosit 
Dewasa ini diabetes melitus telah menjadi salah satu masalah kesehatan utama. ${ }^{1}$ Pada tahun 2011 terdapat 366 juta orang menderita diabetes, dan diperkirakan akan meningkat menjadi 552 juta orang pada tahun 2030. ${ }^{1,2}$ Indonesia kini telah menduduki rangking keempat jumlah penyandang diabetes terbanyak setelah Amerika Serikat, China dan India. ${ }^{3}$

Diabetes melitus merupakan suatu kelompok penyakit metabolik dengan karakteristik hiperglikemia yang terjadi karena kelainan sekresi insulin, kerja insulin, atau kedua-duanya. $^{4-6}$ Pada pasien diabetes melitus tipe-2 terjadi percepatan trombopoiesis dan peningkatan pergantian trombosit atau yang biasa disebut platelet turnover. ${ }^{7-9}$ Peningkatan dua kali lipat pergantian trombosit terjadi karena waktu kelangsungan hidup trombosit yang menurun dan peningkatan masuknya trombosittrombosit baru ke dalam sirkulasi. ${ }^{10}$ Ketika pergantian trombosit meningkat, terjadi peningkatan ukuran trombosit yang lebih besar dan reaktif yang dilepaskan dari megakariosit sumsum tulang belakang, ${ }^{11}$ sehingga bersifat lebih trombogenik. ${ }^{12}$

Trombosit pada pasien diabetes melitus telah terbukti menjadi hiperreaktif dengan peningkatan adesi, aktivasi, dan agregasi trombosit. $^{7}$ Beberapa mekanisme yang diduga berperan dalam peningkatan reaktivitas trombosit antara lain: disebabkan oleh kelainan metabolisme dan seluler yang dikelompokkan ke dalam kategori: hiperglikemia, resistensi insulin, dan kondisikondisi metabolik yang berkaitan dengan penyakit diabetes (obesitas, dislipidemia dan inflamasi), serta kelainan-kelainan seluler lainnya. ${ }^{7,13}$

Pasien diabetes melitus memiliki risi-ko tinggi terhadap komplikasi kardiovas-kular dan kejadian aterotrombosis yang berulang dibandingkan dengan pasien non-diabetes. ${ }^{7}$ Risiko kematian karena komplikasi penyakit jantung pada diabetes dapat meningkat dua sampai empat kali lipat pada perempuan dan laki-laki. ${ }^{10,14,15}$

Tiga puluh tiga laporan penelitian menunjukkan penggunaan aspirin mencapai
41\%, dan 27-73\% digunakan pada mereka dengan indikasi pencegahan primer dan sekunder terhadap penyakit kardiovaskular. ${ }^{16}$ Aspirin menghambat sintesis tromboksan oleh siklooksigenase trombosit dan telah digunakan sebagai pencegahan primer dan sekunder terhadap terjadinya kejadian kardiovaskular pada orang dengan diabetes. ${ }^{14-17}$

Hasil penelitian yang ditemukan oleh Erhart dkk, ${ }^{18}$ menyatakan bahwa terjadi peningkatan jumlah trombosit pada dosis tertentu setelah menggunakan aspirin, sedangkan peneltian yang dilakukan oleh Abaci dkk, ${ }^{19}$ menemukan bahwa tidak terjadi perbedaan signifikan pada jumlah trombosit sebelum dan setelah menggunakan aspirin. Teori yang lain pun mengatakan bahwa penggunaan obat anti inflamasi non-steroid (OAINS), termasuk aspirin dapat menyebabkan terjadinya penurunan jumlah trombosit. ${ }^{20}$ Penelitian ini bertujuan untuk mengetahui perbedaan jumlah trombosit pada pasien diabetes melitus tipe-2 yang menggunakan aspirin dan tidak menggunakan aspirin.

\section{METODE}

Penelitian ini bersifat deskriptif analitik dengan desain cross sectional. Subjek penelitian berjumlah 112 orang, 56 orang yang menggunakan aspirin dan 56 orang lainnya tidak menggunakan aspirin yang memenuhi kriteria inklusi di RSUP Prof. DR. R. D. Kandou Manado.

Teknik pengambilan sampel, yaitu dengan memilih sampel yang memenuhi kriteria inkusi: usia 40-70 tahun, terbukti menderita diabetes melitus tipe-2 yang merupakan pasien rawat jalan, jenis kelamin perempuan dan laki-laki, menggunakan aspirin dengan dosis 75-162 mg yang sampai pada pemeriksaan sedang menggunakan aspirin minimal dua minggu terakhir dan yang tidak pernah menggunakan aspirin atau obat antiplatelet atau OAINS lainnya. Adapun kriteria eksklusi pada penelitian ini ialah: riwayat merokok dan minum alkohol; individu yang menggunakan obat antiplatelet lain, obat antiinflamasi nonsteroid 
(OAINS) lain, heparin, obat antimikroba (Linezolid, rifampin, sulfonamides, vancomycin), obat kemoterapi (Fludarabine, oxaliplatin), obat sedatif dan antikonvulsan (Carbamazepine, phenytoin, valproic acid dan diazepam), dan obat diuretik (Chlorothiazide); Individu yang menderita penyakit infeksi, keganasan, trauma dan memiliki riwayat splenektomi sebelumnya yang dapat mempengaruhi jumlah trombosit.

Pengumpulan data dilakukan dengan menggunakan data sekunder dari catatan rekam medik. Data yang diperoleh kemudian dikelompokkan berdasarkan variabel penelitian, lalu dipaparkan dalam gambar, tabel dan teks.

\section{HASIL}

Dari 112 orang total subjek penelitian yang memenuhi kriteria inklusi, ditemukan lebih banyak subjek yang berusia tua sebesar $75 \%$ dan jenis kelamin perempuan sebesar 58,9\%. Pada penelitian ini data Indeks Massa Tubuh (IMT) diklasifikasikan berdasarkan kriteria IMT menurut WHO pada orang Asia dan ditemukan subjek penelitian pada umumnya termasuk dalam klasifikasi obes I (IMT 25-29,9 $\mathrm{kg} / \mathrm{m}^{2}$ ) sebesar $42,9 \%$ dan yang paling sedikit subjek termasuk dalam klasifikasi berat badan kurang (IMT $<18,5 \mathrm{~kg} / \mathrm{m}^{2}$ ) yaitu sebesar 0,9\% (Tabel 1).

Pada penelitian ini subjek penelitian yang menggunakan aspirin memiliki jumlah trombosit terendah yaitu $139.000 / \mu \mathrm{L}$ dan tertinggi yaitu $377.000 / \mu \mathrm{L}$, sehingga diperoleh nilai rata-rata 264.017,86 yang dapat dibulatkan menjadi $264.000 / \mu \mathrm{L}$ dengan simpang baku55.533,934 (Tabel 2).

Gambar 1 menunjukkan bahwa hanya terdapat satu orang (2\%) yang memiliki jumlah trombosit rendah yaitu kurang dari 150.000/ $\mu \mathrm{L}$ dan terdapat 55 orang (98\%) yang memiliki jumlah trombosit normal yaitu 150.000-450.000/ $\mu \mathrm{L}$.

Pada penelitian ini subjek penelitian yang tidak menggunakan aspirin memiliki jumlah trombosit terendah yaitu 184.000/ $\mu \mathrm{L}$ dan tertinggi yaitu $551.000 / \mu \mathrm{L}$, sehingga

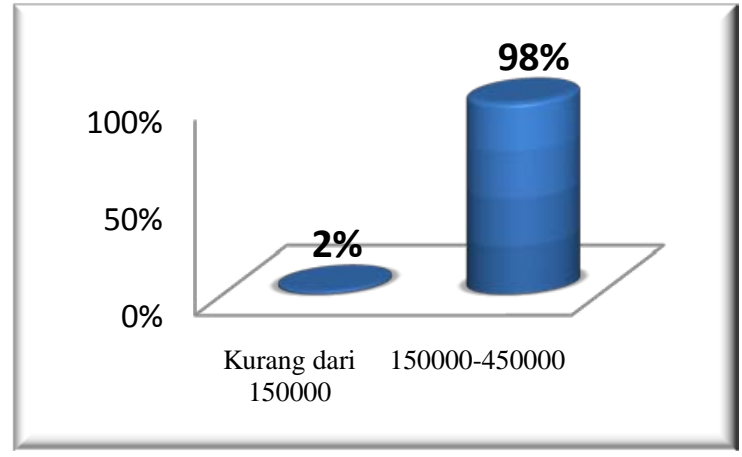

Gambar 1. Distribusi subjek penelitian berdasarkan jumlah trombosit pada pasien diabetes melitus tipe-2 yang menggunakan aspirin.

diperoleh nilai rata-rata 295.803,57 yang dapat dibulatkan menjadi $296.000 / \mu \mathrm{L}$ dengan simpang baku=81.649,900. (Tabel 3).

Gambar 2 menunjukkan bahwa terdapat 53 orang (95\%) yang memiliki jumlah trombosit normal yaitu 150.000-450.000/ $\mu \mathrm{L}$ dan hanya terdapat tiga orang (5\%) yang memiliki jumlah trombosit tinggi yaitu lebih dari 450.000/ $\mu \mathrm{L}$.

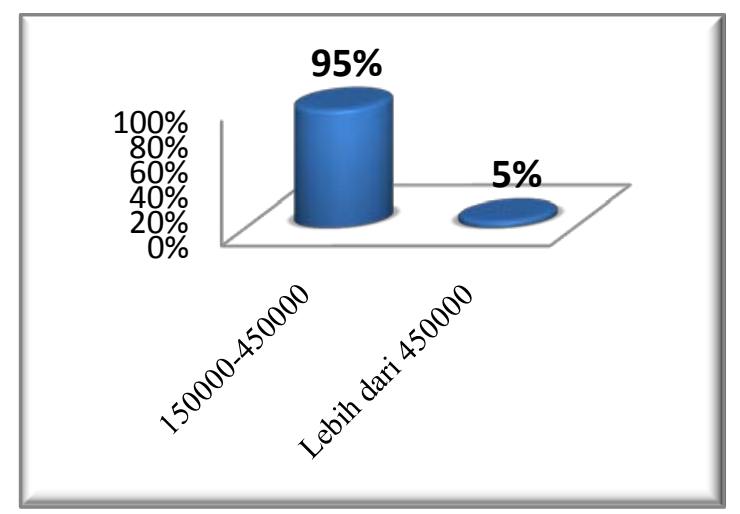

Gambar 2. Distribusi subjek penelitian berdasarkan jumlah trombosit pada pasien diabetes melitus tipe-2 yang tidak menggunakan aspirin.

Uji Mann-Whitney menunjukkan nilai signifikasi p > 0,05, yaitu 0,059 (Tabel 4), hasil ini menunjukkan bahwa tidak ter-dapat perbedaan jumlah trombosit pada pasien diabetes melitus tipe-2 yang meng-gunakan aspirin dan tidak menggunakan aspirin. 
Tabel 1. Karakteristik subjek penelitian berdasarkan usia, jenis kelamin, dan indeks massa tubuh.

\begin{tabular}{cccc}
\hline Karakteristik & Klasifikasi & Frekuensi & Persentasi (\%) \\
\hline \multirow{2}{*}{ Usia } & Muda dan Dewasa (15-49 Tahun) & 28 & 25 \\
& Tua ( $\geq 50$ Tahun) & 84 & 75 \\
Jenis Kelamin & Laki-laki & 46 & 41,1 \\
& Perempuan & 66 & 58,9 \\
& $<18,5 \mathrm{~kg} / \mathrm{m}^{2}$ & 1 & 0,9 \\
Indeks Massa & $18,5-22,9 \mathrm{~kg} / \mathrm{m}^{2}$ & 24 & 21,4 \\
Tubuh (IMT) & $23-24,9 \mathrm{~kg} / \mathrm{m}^{2}$ & 24 & 21,4 \\
& $25-29,9 \mathrm{~kg} / \mathrm{m}^{2}$ & 48 & 42,9 \\
& $\geq 30 \mathrm{~kg} / \mathrm{m}^{2}$ & 15 & 13,4 \\
\hline
\end{tabular}

Tabel 2. Data jumlah trombosit pada diabetes melitus tipe 2 yang menggunakan aspirin.

\begin{tabular}{ccccc}
\hline Variabel & $\begin{array}{c}\text { Nilai } \\
\text { terendah }\end{array}$ & Nilai tertinggi & $\begin{array}{c}\text { Nilai } \\
\text { Rata-rata }\end{array}$ & $\begin{array}{c}\text { Simpang } \\
\text { Baku }\end{array}$ \\
\hline $\begin{array}{c}\text { Pasien DM tipe 2 yang } \\
\text { menggunakan aspirin }\end{array}$ & 139.000 & 377.000 & $264.017,86$ & $55.533,934$ \\
\hline
\end{tabular}

Tabel 3. Data jumlah trombosit pada diabetes melitus tipe 2 yang tidak menggunakan aspirin.

\begin{tabular}{ccccc}
\hline Variabel & $\begin{array}{c}\text { Nilai } \\
\text { terendah }\end{array}$ & Nilai tertinggi & $\begin{array}{c}\text { Nilai } \\
\text { Rata-rata }\end{array}$ & $\begin{array}{c}\text { Simpang } \\
\text { Baku }\end{array}$ \\
\hline $\begin{array}{c}\text { Pasien DM tipe 2 yang tidak } \\
\text { menggunakan aspirin }\end{array}$ & 184.000 & 551.000 & $295.803,57$ & $81.649,900$ \\
\hline
\end{tabular}

Tabel 4. Perbandingan jumlah trombosit pada pasien diabetes melitus tipe 2 yang menggunakan aspirin dan tidak menggunakan aspirin.

\begin{tabular}{cccccc}
\hline Varibel & Kategori & $\begin{array}{c}\text { Nilai } \\
\text { rata-rata }\end{array}$ & Simpang Baku & Nilai p & Signifikasi \\
\hline \multirow{2}{*}{ Trombosit } & $\begin{array}{c}\text { DM tipe } 2 \\
\text { dengan aspirin }\end{array}$ & $264.017,86$ & $55.533,934$ & & \\
\cline { 2 - 4 } 0 & $\begin{array}{c}\text { DM tipe 2 tanpa } \\
\text { aspirin }\end{array}$ & $295.803,57$ & $81.649,900$ & & $<0,05$ \\
\hline
\end{tabular}

Uji Mann-Whitney menunjukkan nilai signifikasi $\mathrm{p}>0,05$, yaitu 0,059 (Tabel 4), hasil ini menunjukkan bahwa tidak terdapat perbedaan jumlah trombosit pada pasien diabetes melitus tipe-2 yang menggunakan aspirin dan tidak menggunakan aspirin.

\section{BAHASAN}

Pada penelitian ini jumlah subjek penelitian yang memenuhi kriteria inklusi ialah 112 orang yang diambil dari data rekam medik di Poliklinik EndokrinMetabolik bagian Penyakit Dalam RSUP. Prof. Dr. R. D. Kandou Manado.

Pada penelitian ini usia dikategorikan berdasarkan klasifikasi World Health Organization (WHO) yaitu usia muda dan dewasa (15-49 tahun) serta usia tuą (50 tahun). ${ }^{21}$ Hasil penelitian ini menunjukkan jumlah usia tua lebih banyak dibandingkan dengan usia muda dan dewasa. Hal yang 
sama juga ditemukan pada penelitian yang dilakukan oleh Dinas Kesehatan Masyarakat di Kanada pada tahun 2011 yang menyatakan bahwa prevalensi penyakit diabetes melitus tipe-2 meningkat berdasarkan usia dan ditemukan usia tua lebih banyak dibandingkan usia muda. Peningkatan terus terjadi hingga mencapai puncak usia 70-79 tahun dan kemudian mengalami penurunan pada usia 80 tahun atau lebih. Bertambahnya usia merupakan salah satu faktor risiko terjadinya penyakit diabetes. ${ }^{22}$

Pada penelitian ini jenis kelamin perempuan ditemukan lebih banyak, yaitu 66 orang (58,9\%), sedangkan laki-laki ialah 46 orang $(41,1 \%)$. Hal ini disebabkan perempuan cenderung memiliki berat badan lebih (obesitas), aktifitas fisik yang kurang, serta adanya pengaruh faktor hormonal yang merupakan faktor risiko terjadinya diabetes. $^{23,24}$

IMT pada subjek penelitian diklasifikasikan berdasarkan klasifikasi IMT menurut WHO pada orang Asia. ${ }^{25}$ Pada umumnya subjek termasuk dalam kriteria obes I (IMT 25-29,9 kg/m²) yaitu sebanyak 48 orang dan yang paling sedikit termasuk dalam klasifikasi berat badan kurang (IMT $<18,5 \mathrm{~kg} / \mathrm{m}^{2}$ ) yaitu sebanyak satu orang. Peningkatan lemak tubuh pada umumnya berkaitan dengan risiko penyakit-penyakit metabolik seperti; diabetes melitus tipe 2, hipertensi, dan dislipidemia, ${ }^{26}$ sedangkan berat badan kurang berkaitan dengan populasi usia tua, ${ }^{27,28}$ tetapi mekanisme pasti belum diketahui. ${ }^{28}$

Pada umumnya jumlah trombosit yang ditemukan pada pasien diabetes melitus tipe-2 yang menggunakan aspirin masih termasuk dalam rentang normal (150.000450.000/ $\mu \mathrm{L})$. Hal ini disebabkan aspirin berperan dalam menghambat fungsi enzim cyclooxygenase-1 (COX-1) pada trombosit secara ireversibeldan juga menghambat produksi tromboksan $\mathrm{A}_{2},{ }^{14,15,17,29-31}$ dan tidak berpengaruh terhadap jumlah trombosit. $^{32}$

Pada penelitian ini terdapat seorang pasien diabetes melitus tipe-2 yang menggunakan aspirin dan memiliki jumlah trombosit rendah $(<150.000 / \mu \mathrm{L})$. Jumlah trombosit yang rendah atau trombositopenia dapat disebabkan karena penurunan produksi oleh sumsum tulang karena reduksi selektif megakariosit yang berkaitan dengan penggunaan obat-obatan (sulfanamida, thiazid, obat anti inflamasi nonsteroid), bisa juga disebabkan karena adanya peningkatan pemakaian trombosit yang berkaitan dengan komplikasi pada diabetes melitus tipe $2 .^{20}$

Jumlah trombosit yang ditemukan pada pasien diabetes melitus tipe- 2 yang tidak menggunakan aspirin pada umumnya masih termasuk dalam rentang normal (150.000$450.000 / \mu \mathrm{L})$. Hasil penelitian ini sama dengan penelitian yang ditemukan oleh Zuberi dkk ${ }^{12}$ yang menyatakan bahwa tidak terdapat perubahan dalam jumlah trombosit pada orang dengan diabetes.

Dalam penelitian ini juga ditemukan tiga orang yang memiliki jumlah trombosit tinggi $(>450.000 / \mu \mathrm{L})$ atau yang dikenal dengan istilah trombositosis. Trombosito-sis berkaitan dengan meningkatnya risiko trombosis. $^{33}$ Trombosis adalah terdapatnya bekuan darah yang bersifat stasioner di sepanjang dinding pembuluh darah yang sering menyebabkan obstruksi vaskular ${ }^{34}$ dan berperan terhadap peningkatan kejadian penyakit kardiovaskular pada diabetes melitus. $^{33}$

Pada penelitian ini ditemukan nilai ratarata jumlah trombosit pada pasien DM tipe2 yang menggunakan aspirin lebih rendah $(264.000 / \mu \mathrm{L})$ dibandingkan dengan yang tidak menggunakan aspirin (296.000/ $\mu \mathrm{L})$ yang berarti jika dilihat secara nominal terdapat perbedaan antara kedua variabel, namun jika diuji secara statistik yaitu dengan menggunakan uji Mann-Whitney ditemukan nilai signifikasi $\mathrm{p}>0,05$, yaitu 0,059 . Hasil ini menunjukkan bahwa tidak terdapat perbedaan signifikan jumlah trombosit pada pasien diabetes melitus tipe-2 yang menggunakan aspirin dan tidak menggunakan aspirin. Hal ini dapat terjadi karena aspirin hanya berpengaruh terhadap fungsi trombosit yang berperan dalam menghambat fungsi enzim cyclooxygenase- 
1 (COX-1) pada trombosit secara ireversibeldan juga menghambat produksi tromboksan $\mathrm{A}_{2}$, $14,15,17,29-31$ dan bukan pada jumlah trombosit. $^{32}$

Hal yang sama juga ditemukan pada penelitian yang dilakukan oleh Abaci dkk ${ }^{20}$ yang menyatakan bahwa tidak terdapat perbedaan jumlah trombosit sebelum dan sesudah menggunakan aspirin pada 102 pasien diabetes melitus tipe-2. Berbeda dengan hasil penelitian yang ditemukan oleh Erhart $\mathrm{dkk}^{19}$ yang menyatakan bahwa pada pemeriksaan serial darah, penghentian tibatiba pada relawan sehat yang diterapi dengan 250mg aspirin tiap hari menunjukkan peningkatan jumlah trombosit dan massa trombosit dalam 24 jam selama terapi dalam tujuh hari. Hal ini menunjukkan bahwa aspirin mungkin mempengaruhi sirkulasi massa trombosit (perkalian antara jumlah trombosit dan volum trombosit rata-rata) dalam keadaan tertentu. Hal ini dapat terjadi karena peningkatan produksi trombosit, yang menunjukkan bahwa produksi trombosit tidak hanya diatur oleh massa total pada kehadiran trombosit dalam sirkulasi tetapi juga oleh massa yang secara fisiologis merupakan trombosit intak, karena memburuknya fungsi trombosit oleh aspirin yang tampaknya diperkirakan dari sumsum tulang. Perubahan ini dapat merupakan efek langsung dari aspirin pada maturasi megakariosit atau dapat diperantarai melalui kehadiran atau ketidakhadiran dari pembawa pesan yang dilepaskan oleh pengaktifan atau tidak aktifnya trombosittrombosit, tetapi tanpa penghentian tiba-tiba dari terapi aspirin pada pemeriksaan serial darah, aspirin tidak mempengaruhi jumlah trombosit. $^{19}$

Perbedaan hasil penelitian sebelumnya dapat disebabkan subjek penelitian yang berbeda (pasien diabetes melitus tipe-2 dan individu sehat) dan dosis aspirin yang berbeda serta efek penghentian secara tiba-tiba dari aspirin. Pada penelitian ini juga terdapat keterbatasan penelitian seperti: terbatasnya jumlah sampel, data yang digunakan ialah data sekunder dari rekam medik, dan hanya melihat pengaruh aspirin terhadap jumlah trombosit tanpa adanya pemeriksaan lain, seperti: kadar trombopoietin yang juga dapat mempengaruhi jumlah trombosit.

\section{SIMPULAN}

Berdasarkan hasil penelitian dan pembahasan di atas dapat disimpulkan bahwa tidak terdapat perbedaan signifikan antara jumlah trombosit pada pasien diabetes melitus tipe-2 yang menggunakan aspirin dan tidak menggunakan aspirin.

\section{UCAPAN TERIMA KASIH}

Ucapan terima kasih disampaikan kepada para dosen penguji, yaitu dr. Juanita Langi, SpPD-KEMD dan Prof. Dr. dr. Karel Pandelaki, SpPD-KEMD yang telah memberikan koreksi, sumbangan pemikiran dan kritik yang membangun dan kepada semua pihak yang secara langsung atau tidak langsung telah menumbuhkan gagasan pada penulisan artikel ini.

\section{DAFTAR PUSTAKA}

1. International Diabetes Federation. Global diabetes plan 2011-2021. 2011. Available from:http://www.idf.org/sites/default/files/G lobal Diabetes_Plan_Final.pdf [Accesed on Nov. $7^{\text {th }}$ 2012].

2. International Diabetes Federation. One adult in ten will have diabetes by 2030. 2011. Available from:http://www.idf.org/mediaevents/press-releases/2011/diabetes-atlas5th-edition[Accesed on Nov. $7^{\text {th }} 2012$ ].

3. Pusat Data dan Informasi PERSI. RI Rangking Keempat Jumlah Penderita Diabetes Terbanyak Dunia. 2011. Available from:http://www.pdpersi.co.id/content/news .php?mid=5\&nid=618\&catid=23 [Accesed on Nov. $\left.7^{\text {th }} 2012\right]$.

4. Perkumpulan Endokrinologi Indonesia (PERKENI). Konsensus pengelolaan dan pencegahan diabetes mellitus tipe 2 di Indonesia. Jakarta; 2011.

5. Purnamasari D. Diagnosis dan klasifikasi diabetes mellitus. Dalam: Sudoyo AW, Setiyohadi B, Alwi I, Simadibrata M, Setiati S, editors. Buku Ajar Ilmu Penyakit Dalam. Jilid III, Edisi V. Jakarta: Interna Publishing; 2009; h.1880-82. 
6. Soegondo S. Diagnosis dan klasifikasi diabetes melitus terkini. Dalam: Soegondo S, Soewondo P, Subekti I, editors. Penatalaksanaan Diabetes Melitus Terpadu. Edisi 2. Jakarta: Balai Penerbit Fakultas Kedokteran Indonesia, 2011; h.19-30.

7. Ferreiro JL, Angiolillo DJ. Diabetes and antiplatelet therapy in acute coronary syndrome. Circulation. 2011;123:798-813.

8. Capodanno D, Patel A, Dharmashankar K, Ferreiro JL, Ueno M, Kodali M, et al. Pharmacodynamic effects of different aspirin dosing regimens in type 2 diabetes melitus patients with coronary artery disease. Circ Cardiovasc Interv. 2011;4:180-7.

9. Yngen M. Platelet hyperactivity in diabetes melitus. Eur J Cardiol. 2005;1-4.

10. Kraw M. Antiplatelet therapy in diabetes. Endocrinology. 2002;2:118-21.

11. Grove EL, Hvas AM, Mortesen SB, Larsen SB, Kristensen SD. Effect of platelet turnover on whole blood aggregation in patients with coronary artery disease. J Thromb Haemost. 2011;9:185-91.

12. Zuberi BF, Akhtar N, Afsar S. Comparison of mean platelet volume in patients with diabetes melitus, impaired fasting glucose and non-diabetic subjects. Singapore Med J. 2008;49(2):114-6.

13. Kodiatte TA, Manikyam UK, Rao SB, Jagadish TM, Reddy M, Lingaiah HK, et al. Mean platelet volume in type 2 diabetes melitus. J Lab Physicians 2012;4:5-9

14. Yaturu S, Mousa S. Diabetes and aspirin resistance. Dalam: Zimering $\mathrm{M}$, editor. Recent advances in the pathogenesis prevention and management of type 2 diabetes and its complications. 2011. Available from: http://www.intechopen. com/books/recent-advancesin-the-

pathogenesis-prevention-and-managementof-type-2-diabetes-and-its-

complications/diabetes-andaspirinresistance. [Accesed on Nov. 11 ${ }^{\text {st }} 2012$ ].

15. American Diabetes Association. Aspirin therapy in diabetes. Diabetes care. 2004;27:1-2.

16. Law EH, Simpson SH. Aspirin use rates in diabetes: A systematic review and crosssectional study. Canadian Journal of Diabetes. 2010;34(3):211-7.

17. Fisher M. Diabetes as a cardiovascular disease. Dalam: Barnett AH, editor. Diabetes best practice research compendium. Spain: Elsevier; 2006.h.83.
18. Erhart S, Beer JH, Reinhart WH. Influence of aspirin on platelet count and humans. Acta Haematol. 1999;101:140-44.

19. Abaci A, Yilmaz Y, Caliskan M, Bayram F, Cetin M, Unal A. Effect of increasing doses of aspirin on platelet function as measured by PFA-100 in patients withdiabetes. Thromb Res. 2005;116:46570 .

20. Mehta A, Hoffbrand V. At a glance hematologi. Edisi 2. Jakarta: Erlangga; 2008. h. 73-75.

21. Kurniawan E, Purnama IK, Sumpeno S. Analisa rekam medis untuk menentukan pola kelompok penyakit menggunakan klasifikasi dengan decision tree J48. 2011.

22. Pottie K, Jaramillo A, Lewin G, Dickinson J, Bell N, Brauer $P$, et al. Recommendations on screening for type 2 diabetes in adults. Can Med Assoc J. 2012;184:1687-96.

23. Black SA. Diabetes, diversity, and disparity: what do we do with the evidence?. Am J Public Health. 2002;92:543-8.

24. Revis JN, Keene S. Type II diabetes in american women over 40: obesity and menopause. Internet Journal of Health. 2007;6:1.

25. Sidartawan S. Obesitas. Dalam: Sudoyo AW, Setiyohadi B, Alwi I, Simadibrata M, Setiati S, editors. Buku Ajar Ilmu Penyakit Dalam. Jilid III, Edisi V. Jakarta: Interna Publishing; 2009. h.1978.

26. Bays HE, Chapman RH, Grandy. The relationship of body mass index to diabetes mellitus, hypertension and dyslipidaemia: comparison of data from two national surveys. Int J Clin Pract. 2007;61:737-47.

27. Stetson B, Mokshagundam SP. Nutrition and lifestyle change in older adults with diabetes melitus and metabolic syndrome. Dalam: Bales CW, Ritchie CS, editors. Handbook of clinical nutrition and aging. Edisi 2. New York: Humana Press; 2009. h. 282.

28. Sairenchi $T$, Iso $H$, Irie $F$, Fukasawa $\mathbf{N}$, Ota H, Muto T. Underweight as a predictor of diabetes melitus in older adults: A large cohort study. JAMA. 2007.

29. Astuti KW. Kombinasi asetosal dan ekstrak buah mengkudu (morinda citrifolia L.) dapat memperpanjang waktu perdarahan dan koagulasi pada mencit. [Tesis]. Denpasar: Universitas Udayana; 2011.

30. Kadar D. Anti-inflamatory Analgesics. 
Dalam: Kalant H, Garant DM, Mitchell J, editors. Principles of Medical Pharmacology. Edisi 7. Canada: Elsevier; 2007.h.365-7.

31. Wientong $P$, Jonjarornprasert $W$, Panomvana D. Platelet agrgregation and serum tromboksan $\mathrm{B}_{2}$ level after taking 60 $\mathrm{mg} /$ day of aspirin in type 2 diabetic Thai patients. Int J Pharm Sci. 2011;3:47-50.
32. Mitchell RN, Kumar, Abbas, Fausto. Buku saku dasar patologis penyakit robbins \& cotran. Edisi 7. Jakarta: EGC; 2008. h. 377-80

33. Daly ME. Determinants of platelet count in human. Haematol. 2011;96:10-3.

34. Kamus kedokteran dorland. Edisi 29. Jakarta: EGC; 2002. h. 2238-9. 